\title{
Regional Allocation of Total Energy Consumption over the Case of Sichuan Province
}

\author{
Y.L. HU \& W.B. Huang \& J. Wang \& S.J. Chen \\ Sichuan University, Chengdu, China \\ J. Zhang \\ Sichuan Economy Development Research Institution, Chengdu, China
}

\begin{abstract}
In the context of assessment and optimization of energy consumption issues, this paper puts forward an integrated approach for regional decomposition of the energy consumption cap over the case of Sichuan Province. Based on the regional level of economic development, efficiency of energy utilization, and provincial characteristics, a classifying-evaluation system is established to divide 21 regions of Sichuan Province into 4 categories, which serve the primary allocation_ a linear programming model maximizing total energy consumption while optimally allocating the defined reduction target of energy consumption growth rate to each category according to the country issued target of energy consumption cap. Integrating the average annual energy consumption growth rate of each region during the $11^{\text {th }}$ Five-Year Plan and the planned one during the $12^{\text {th }}$ Five-Year Plan, the secondary allocation gives the differential treatment to the reduction targets of regions from each category, and thus works out the control energy consumption cap of each region relatively.
\end{abstract}

KEYWORD: Regional decomposition; Total energy consumption; Classifying-evaluation; Llinear programming; Sichuan Province

\section{INTRODUCTION}

As the economy grows and people's living standard improves, energy has become the bottleneck of the world's development, especially the developing countries. Take China: The average annual growth rate of primary energy consumption from 2001 to 2011 is $9.64 \%$, much higher than that of developed countries-America (0.04\%), Japan (-0.71\%), and France $(-0.62 \%)$. For limited energy resources, Chinese external dependence of fossil energy continually rises (coal: 14\%, oil: $56.6 \%$, nature gas: $29 \%$ in 2012), bringing certain threat to national energy security that has attracted much attention by governmental departments. Set forth in national "12th Five-Year Plan" as an obligatory target, energy intensity in 2015 must decrease by 16\% compared with the level of 2010. Furthermore, regional decomposition of the indicator was subsequently required. Although certain achievements were made, the drop of energy intensity could still not stop the upward total energy consumption, which has aroused more concern in both academia and politics. The 18th Party Congress Report puts forward to controlling the energy consumption cap. In a sense, the regional decomposition of energy consumption will be probably carried out for some time. Carrying out the research on approach for regional decomposition of energy consumption cap, as a consequence, is very urgent and significant.

Literatures on decomposition of related energy saving indicators, as yet, almost focus on energy intensity (Fan and Wang, 2009; Zhai et al., 2007), while that of energy consumption cap is more effective. Despite its late start and complication, there is still much experience to follow. Xing and Shan (2012) indicated that the control of energy consumption should more focus on fossil energy and market-oriented policy. Comes (2007) researched the emission allowance of $\mathrm{CO} 2$ among countries based on the certain total CO2 emissions. Phylipsen (1998) indicated "triple therapy", allocating the carbon-reduction target of Kyoto Protocol to its member states. Wang et al. (2013) proposed an improved zero sum gains data envelopment analysis optimization model to solve the regional allocation of $\mathrm{CO} 2$ emissions allowance over provinces. Liu et al. (2012) put forward a decomposition model for China's national renewable energy total target. Sun et al. (2012) provided a new approach to solve the problem of energy consumption quota allocation based on the environmental DEA technology and ZSG-DEA. 
Although extensive academic research has been conducted, regional decomposition of energy consumption cap remains an issue to be solved. As Ruan and Ya (2011) notes, the control of energy consumption cap will bring more directly impact on regional economic development compared with other energy saving targets. Thus, in additional to maximizing general efficiency of energy utilization, the decomposition approach should still focus on the equity especially applied to the regions where regional disparity is significant.

\section{MODEL USED}

In terms of multi-objective decision issues, to establish a classifying-evaluation system will be simple and effective for regional decomposition. Nevertheless, considering the connection of regional development plan and 12th Five-Year special plan for energy conservation, average annual energy consumption growth rate, the control target chosen by national work program of reasonably controlling the energy consumption cap in the decomposition system, will cause serious inequity while applied to study area where disparity of regional economy is prominent. As a consequence, this model defines a reduction target which based on the planned energy consumption growth (see details in chapter 2.3) as the control index in decomposition system.

\subsection{Calculation of the planned energy consumption growth}

On account to the pre-industrial period for most of the cities in Sichuan Province, the economy development generally depends heavily on the massive energy consumption. Based on the regional planned economy growth in distributed plan, the energy intensity, set forth in the Sichuan 12th FiveYear special plan for energy saving as an obligatory target, to a certain extent restricts the energy consumption cap, which could be set as the planned one. Under this definition, regional planned energy consumption can be calculated by Eq. (1).

$$
V_{i p}=\left(1+a_{i}\right) \cdot\left(1-b_{i}\right)^{1 / 5}-1
$$

Where $V_{i p}$ is the planned energy consumption of City $i . a_{i}$ is the average annual economy growth rate of City $i$ during 12 th five year. $b_{i}$ is the average annual energy intensity decline rate during 12 th five year.

\subsection{Classify-evaluation system}

Taking into consideration of economy development, efficiency of energy utilization and regional characteristics, a classify-evaluation system is established with 8 indexes (see details in Table 1). The weighting of each index is decided through expert marking method.

Table 1. Classifying-evaluating System for Decomposition

\begin{tabular}{|c|c|c|c|c|}
\hline \multirow{9}{*}{$\begin{array}{l}\text { Classifying } \\
\text { \& evaluation } \\
\text { system }\end{array}$} & Name & Indicator & Num & Weighting \\
\hline & \multirow{4}{*}{$\begin{array}{l}\text { Economic } \\
\text { development }\end{array}$} & GDP per capita & 1 & 0.10 \\
\hline & & Local government financial revenue per capita & 2 & 0.15 \\
\hline & & Proportion of the tertiary industry in GDP & 3 & 0.15 \\
\hline & & Energy consumption per capita & 4 & 0.15 \\
\hline & \multirow{2}{*}{$\begin{array}{l}\text { Efficiency of energy } \\
\text { utilization }\end{array}$} & Energy consumption per unit of GDP & 5 & 0.10 \\
\hline & & Energy consumption per unit of industrial added value & 6 & 0.10 \\
\hline & \multirow{2}{*}{$\begin{array}{l}\text { Regional } \\
\text { characteristics }\end{array}$} & Resident population at year-end & 7 & 0.10 \\
\hline & & Defined category & 8 & 0.15 \\
\hline
\end{tabular}

* "Defined category" refers to the 4 kinds of regions given by Sichuan 12th Five-Year Special Plan for Energy Saving where cities of Panzhihua, Leshan, Deyang et al. are defined as the first kind of region with the biggest responsibility for energy saving, and so on for the rest. In this system, we set the value 4, 3, 2, 1 to quantify the regions from the first to the last kind relatively.

\subsection{Primary allocation of reduction target}

On account of the disparity in fiscal capacity, technology and innovation strength, regions in different categories have big gaps in both ability and responsibility to control the energy consumption growth. To optimally solve the overall level of reduction target for each category upon their planned energy consumption growth rate, the primary allocation will be unfolded as following steps:

Step 1: Calculate the reduction target of whole province.
The reduction target of whole province can be calculated by Eq. (2) and Eq. (3).

$$
\begin{aligned}
& \Delta V=V_{p}-V_{c} \\
& V_{p}=\left(\frac{\sum_{i} E_{i o}\left(1+V_{i p}\right)^{5}}{E_{0}}\right)^{1 / 5}-1
\end{aligned}
$$

Where $\Delta \mathrm{V}$ is the reduction target of whole province, $V_{p}$ is the regional planned growth rate of energy demand, $V_{c}$ is the energy consumption growth rate cap during 12th five year released by 
central government, $E_{0}$ is the total energy consumption in based period, $\mathrm{E}_{\mathrm{io}}$ is the energy consumption of City $\mathrm{i}$ in based period.

Step 2: Analyzing the bound of regional reduction target.

Through observation of regional energy consumption in 2010, the statistical regularity for distributed regions can be summarized as follows:

If $V_{i}(1)>V(1)$, more than $80 \%$ cities satisfy: $\mathrm{V}_{\mathrm{i}}(1) \leq 1.42 \mathrm{~V}(1)$.

If $\mathrm{V}_{\mathrm{i}}(1)<V(1)$, more than $80 \%$ cities satisfy: $\mathrm{V}_{\mathrm{i}}(1) \geq 0.54 \mathrm{~V}(1)$.

Where $V_{i}(1)$ is the average annual energy consumption growth rate of City i during 11th five year, $V(1)$ is the average annual energy consumption growth rate of whole province during 11 th five year.

In consequence, we set $1.42 \Delta \mathrm{V}$ as the ceiling of regional reduction target $\left(\Delta \mathrm{V}_{\text {imax }}\right)$ while $0.54 \Delta \mathrm{V}$ as the floor $\left(\Delta V_{\text {imin }}\right)$.

Step 3: Analyzing the reduction target of each category

Based on the principle of equity, gradient and operability, primary allocation performs in such a way that, each category gets a gradient reduction target of energy consumption growth rate while quota of whole province could be maximum utilized. Thus the primary allocation could be established as a linear programming model with objective function and constraint conditions as follows:

Maximize Objective Function:

Total energy consumption of all regions $(\mathrm{E})$ :

$$
\max E=\sum_{j} \sum_{k} E_{k 0}(j)\left[1+V_{k p}(j)-\Delta V(j)\right]^{5}
$$

Subject to:

$$
\begin{aligned}
& \Delta V_{\text {imax }} \geq \Delta V(j) \geq \Delta V(j+1) \geq \Delta V_{\text {imin }} \\
& \Delta V(j)-\Delta V(j+1) \geq\left(\Delta V_{\text {imax }}-\Delta V_{\text {imin }}\right) / 6 \\
& V_{k p}(j)-\Delta V(j) \geq 0.54 V_{c} \\
& E_{0}\left(1+V_{p}-\Delta V\right)^{5} \geq \sum_{j} \sum_{k} E_{k 0}(j)\left[1+V_{k p}(j)-\Delta V(j)\right]^{5} \\
& \Delta V(j)>0 \quad \forall j \in N^{+}
\end{aligned}
$$

Where $E_{k 0}(j)$ is the energy consumption of City $\mathrm{k}$ in Category $\mathrm{j}$ at the end of year 2010, $\mathrm{V}_{\mathrm{kp}}(\mathrm{j})$ is the planned average annual energy consumption growth rate of City $\mathrm{k}$ in Category $\mathrm{j}$ during 12th five year.

The objective function (Eq. (4)) maximizes the total energy consumption of all regions after primary allocation. Eq. (5) is the constraint for giving the boundary of reduction target of each category. Eq. (6) is to ensure the reasonable disparity of reduction target among different categories. Eq. (7) defines the floor of average annual energy consumption growth rate during 12th five year for each region, and the floor value $\left(0.54 \mathrm{~V}_{\mathrm{c}}\right)$ is set on the analogous principle of $\Delta V_{\text {imax }}$ or $\Delta V_{\text {imin. }}$. Eq. (8) makes the total energy consumption of all regions not exceed the country issued control target of energy consumption. Eq. (9) set positive value for all reduction targets. However, the result is not determinate unless appropriate boundary conditions have been set as Eq. (10) and Eq. (11).

Boundary conditions:

$$
\begin{aligned}
& \Delta V(j, j=2)=\Delta V \\
& \Delta V(j)-\Delta V(j+1)=\Delta V(j+1)-\Delta V(j+2)
\end{aligned}
$$

In the boundary conditions, Eq. (10) is set as the reference in Sichuan 12th Five-Year Special Plan for Energy Saving for better connection between the targets of energy consumption cap and energy intensity. Eq. (11) gives the same disparity of reduction target for adjacent categories.

\subsection{Secondary allocation of reduction target}

Taking into consideration of regional annual average energy consumption growth rate during 11th five year and the planned one during 12th five year, secondary allocation differentiates the reduction targets of regions in same category through Eq. (12).

$$
\begin{aligned}
& \Delta V_{k}(j)=\Delta V(j)-0.5 \times \frac{V_{k l}(j)-V_{l}(j)}{\sigma_{j}} \\
& -0.5 \times \frac{V_{k p}(j)-V_{p}(j)}{\sigma_{j}} \quad\left(\sigma_{j}>0\right)
\end{aligned}
$$

Where $\Delta V_{k}(j)$ is the reduction target of City $k$ in Category $j, V_{k l}(j)$ is the average annual energy consumption growth rate of City $\mathrm{k}$ in Category $\mathrm{j}$ while $V_{l}(j)$ is that of Category $j$ during 11th five year, $V_{p}(j)$ is the planned average annual energy consumption growth rate of Category $j$ during 12th five year, $\sigma_{j}$ is the differential factor of Category $j$ which uncrosses the range of reduction targets of different categories and satisfies the following conditions:

(1) For $\forall k$, if $j=1$, Eq. (13) is true.

(2) For $\forall k$, if $j=\max \{j\}$, Eq. (14) is true.

(3) For $\forall k$, if $j \neq 1, \max \{j\}$, both Eq. (13) and Eq. (14) are true.

$$
\begin{aligned}
& \min _{\forall k} \Delta V_{k}(j)>\max _{\forall r} \Delta V_{r}(j+1) \\
& \max _{\forall k} \Delta V_{k}(j)<\min _{\forall s} \Delta V_{s}(j-1)
\end{aligned}
$$

Furthermore, the differential factor can be calculated as following steps:

(1) For $\forall j \in N^{+}$, assuming: $\sigma_{j}=\sigma_{j}^{(0)}$, where $\sigma_{j}^{(0)}$ is the initial value which is usually set up to 1 .

(2) Make judgment for $\sigma_{j}$ in sequence. If $\sigma_{j}$ does not meet the listed conditions, make: 
$\sigma_{j}^{(1)}=\sigma_{j}^{(0)}+\Delta \sigma, \sigma_{j}=\sigma_{j}^{(1)}$ where $\Delta \sigma$ is the increment, $\sigma_{j}^{(1)}$ is the value of differential factor after the first round of adjustment.

(3) Repeat step (2) until $\sigma_{j}^{(t)}$ meet the listed conditions after tth round of adjustments and $\sigma_{j}^{(t)}$ could be set as the end value of differential factor.

Finally, the average annual energy consumption growth rate of each region $\left(V_{k}(j)\right)$ could be calculated by Eq. (15).

$$
V_{k}(j)=V_{k p}(j)-\Delta V_{k}(j)
$$

\section{MODEL APPLICATION}

\subsection{Planned energy consumption growth}

This paper chooses Sichuan Province as demonstration analysis. In the Table 2, the planned energy consumption growth rate of 21 regions is calculated. In this scenario, the average annual energy consumption growth rate of Sichuan Province during 12th five year is expected to $9.95 \%$, far above the country issued control target $(6.23 \%)$ so that the reduction target of whole province $(\Delta V)$ should be at least $3.73 \%$ calculated by Eq. (2).

Table 2. Regional planned energy consumption growth in 12th Five-year plan.

\begin{tabular}{|c|c|c|c|c|c|}
\hline Region & Planned growth & Region & Planned growth & Region & Planned growth \\
\hline Chengdu & $8.16 \%$ & Suining & $9.19 \%$ & Dazhou & $10.19 \%$ \\
\hline Zigong & $8.16 \%$ & Neijiang & $8.87 \%$ & Yaan & $11.32 \%$ \\
\hline Panzhihua & $8.87 \%$ & Leshan & $8.87 \%$ & Bazhong & $11.62 \%$ \\
\hline Luzhou & $8.16 \%$ & Nanchong & $11.06 \%$ & Ziyang & $10.09 \%$ \\
\hline Deyang & $7.90 \%$ & Meishan & $9.13 \%$ & Aba & $25.33 \%$ \\
\hline Mianyang & $10.79 \%$ & Yibin & $9.61 \%$ & Ganzi & $11.62 \%$ \\
\hline Guangyuan & $8.42 \%$ & Guangan & $12.99 \%$ & Liangshan & $11.06 \%$ \\
\hline
\end{tabular}

\subsection{Evaluation and classification}

Based on the classify-evaluation system presented in Table 1, the integrated evaluation index of each region can be calculated by Eq. (2) and Eq. (3). The result and corresponding category are shown in Table 3 where 21 regions are classified according to the follow rules:

Category 1: >1.05; Category 2: 0.85 1.05; Category 3: 0.8 0.85; Category 4: $<0.8$

Table 3. Classification of the regions

\begin{tabular}{|c|c|c|c|c|c|}
\hline Region & $\begin{array}{c}\text { Evaluation } \\
\text { index }\end{array}$ & category & Region & $\begin{array}{c}\text { Evaluation } \\
\text { index }\end{array}$ & category \\
\hline Chengdu & 1.6114 & 1 & Yaan & 0.8307 & 3 \\
\hline Panzhihua & 1.2348 & 1 & Neijiang & 0.8362 & 3 \\
\hline Deyang & 1.1265 & 1 & Guangan & 0.8357 & 3 \\
\hline Leshan & 1.0758 & 1 & Nanchong & 0.8311 & 3 \\
\hline Mianyang & 1.0779 & 1 & Dazhou & 0.8033 & 3 \\
\hline Liangshan & 1.0436 & 2 & Aba & 0.7154 & 4 \\
\hline Yibin & 1.0180 & 2 & Guangyuan & 0.7172 & 4 \\
\hline Zigong & 0.9734 & 2 & Ganzi & 0.7009 & 4 \\
\hline Luzhou & 0.9419 & 2 & Suining & 0.7097 & 4 \\
\hline Meishan & 0.8852 & 2 & Bazhong & 0.4185 & 4 \\
\hline Ziyang & 0.8710 & 2 & & & \\
\hline
\end{tabular}

Evaluation index of each region in Table 3 represents the regional capability of improving energy efficiency as well as controlling the energy consumption cap, which is identical to the decomposition principle of energy intensity listed in Sichuan 12th Five-Year Special Plan for Energy Saving. As a consequence, there should not be great differences between the classification of energy consumption cap and that of energy intensity. The classification of Table 3 is further justified comparing with that of energy intensity in Sichuan 12th Five-Year Special Plan for Energy Saving.

\subsection{Result}

Maximizing Eq. (4) subject to Eq. (5)-(10), the reduction targets of 4 categories are $4.27 \%, 3.73 \%$, $3.18 \%$ and $2.63 \%$ relatively.

Initializing:

$$
\sigma_{1}^{(0)}=\sigma_{2}^{(0)}=\sigma_{3}^{(0)}=\sigma_{4}^{(0)}=1 \quad \Delta \sigma=1
$$

The reduction target of each region can be worked out by Eq. (12) through loop computation of $\sigma_{\mathrm{j}}$ during the secondary allocation. At this point, the regional energy consumption cap in 2015 can be calculated by Eq. (15) further. Based on the quota of each region's energy consumption, the total energy consumption of Sichuan Province in 2015 is $24040.96 \times 104$ tons of standard coal, which is lower than the country issued control target $(24200 \times 104$ tons of standard coal). The results are shown in Table 4. 
Table 4. Result of the regional decomposition of energy consumption cap

\begin{tabular}{|c|c|c|c|c|c|c|}
\hline Region & category & $\begin{array}{c}\text { Primary } \\
\text { reduction }\end{array}$ & $\begin{array}{c}\text { differential } \\
\text { factor }\end{array}$ & $\begin{array}{c}\text { Secondary } \\
\text { reduction }\end{array}$ & $\begin{array}{c}\text { Cap of EC } \\
\text { growth rate }\end{array}$ & $\begin{array}{c}\text { Cap of EC } \\
\text { in 2015 }\end{array}$ \\
\hline Chengdu & 1 & $4.27 \%$ & 5.00 & $4.23 \%$ & $3.93 \%$ & 4550.9 \\
\hline Panzhihua & 1 & $4.27 \%$ & 5.00 & $4.15 \%$ & $4.72 \%$ & 1504.3 \\
\hline Deyang & 1 & $4.27 \%$ & 5.00 & $4.55 \%$ & $3.35 \%$ & 1183.7 \\
\hline Leshan & 1 & $4.27 \%$ & 5.00 & $4.10 \%$ & $4.76 \%$ & 1688.5 \\
\hline Mianyang & 1 & $4.27 \%$ & 5.00 & $4.44 \%$ & $6.35 \%$ & 1442.4 \\
\hline Liangshan & 2 & $3.73 \%$ & 8.00 & $3.54 \%$ & $7.52 \%$ & 1104.2 \\
\hline Yibin & 2 & $3.73 \%$ & 8.00 & $3.74 \%$ & $5.87 \%$ & 1331.9 \\
\hline Zigong & 2 & $3.73 \%$ & 8.00 & $3.92 \%$ & $4.24 \%$ & 838.7 \\
\hline Luzhou & 2 & $3.73 \%$ & 8.00 & $3.70 \%$ & $4.46 \%$ & 1147.2 \\
\hline Meishan & 2 & $3.73 \%$ & 8.00 & $3.83 \%$ & $5.29 \%$ & 1080.5 \\
\hline Ziyang & 2 & $3.73 \%$ & 8.00 & $3.60 \%$ & $6.51 \%$ & 808.5 \\
\hline Yaan & 3 & $3.18 \%$ & 8.00 & $3.14 \%$ & $8.18 \%$ & 394.3 \\
\hline Neijiang & 3 & $3.18 \%$ & 8.00 & $3.14 \%$ & $5.73 \%$ & 1426.1 \\
\hline Guangan & 3 & $3.18 \%$ & 8.00 & $3.00 \%$ & $9.99 \%$ & 1548.5 \\
\hline Nanchong & 3 & $3.18 \%$ & 8.00 & $2.96 \%$ & $8.10 \%$ & 1252.4 \\
\hline Dazhou & 3 & $3.18 \%$ & 8.00 & $3.48 \%$ & $6.70 \%$ & 1591.0 \\
\hline Aba & 4 & $2.63 \%$ & 7.00 & $1.91 \%$ & $23.42 \%$ & 348.6 \\
\hline Guangyuan & 4 & $2.63 \%$ & 7.00 & $2.93 \%$ & $5.49 \%$ & 427.5 \\
\hline Ganzi & 4 & $2.63 \%$ & 7.00 & $2.70 \%$ & $8.92 \%$ & 141.9 \\
\hline Suining & 4 & $2.63 \%$ & 7.00 & $2.66 \%$ & $6.54 \%$ & 732.0 \\
\hline Bazhong & 4 & $2.63 \%$ & 7.00 & $2.65 \%$ & $8.97 \%$ & 389.7 \\
\hline Sum of each region's EC & & & & 24932.7 \\
\hline Total EC of Sichuan Province & & & $6.09 \%$ & 24041.0 \\
\hline The disa & \\
\hline
\end{tabular}

* The disagreement of statistical caliber makes the difference between sum of each region's EC and total EC of Sichuan Province. On account to the difficulty of accurately measuring the statistical error for the next five years, this paper set the error as a constant (the value of 2010) during 12th five year.

\section{CONCLUSION}

This study introduces a composite energy consumption allocation approach that integrates regional level of economic development, efficiency of energy utilization, and provincial characteristics over the case of Sichuan Province. The proposed approach searches for an acceptable solution via more than principle of fairness and associated constraints based on the gap between the country issued control target and the provincial planning one. Finally, the result shows that:

(a) Regions having strong economic strength or heavy industrial structure, such as Chengdu, Panzhihua, Deyang et al., should be controlled at a relatively low level of energy consumption growth rate during 12th five year even though their efficiency of energy utilization might be higher.

(b) Regions of remote mountainous areas and old revolutionary areas, such as Aba, Ganzi, Bazhong et al., should be appropriately eased in the energy consumption controlling because of the weak economy and low level of urbanization.

(c) Regions in the rapid urbanization and industrialization process, such as Yibin, Luzhou, Liangshan et al., should be carefully but necessarily controlled at a appropriate level of energy consumption growth to improve the quality of development.

This research may be helpful to policy makers for the upcoming work of regional decomposition of energy consumption cap. However, the proposed approach is more concern about fairness than efficiency. Thus the decomposition model is more applicable to the provinces (nations) where the whole development is still backward, or disparity of regional economy is prominent, such as Sichuan, Yunnan, Shanxi et al. As for development provinces (nations), the approach released by Sun (2012) may be more applicable while principle of efficiency should be more taken into consideration. Additionally, further studies are needed to effectively balance fairness and efficiency so that not only regions but also industrial sectors could be widely applied.

\section{REFERENCES}

[1] Wang, J., Ma, G. W., Hu, Y. L., Guan, Y. L., and X. L. Dong. 2013. Regional decomposition of an energy saving target: The case of Sichuan Province in China. Energy sources, Part B: Economics, Planning and Policy. 8(3):245-251.

[2] Fan, Y., and Wang, H. B. 2009. The decomposition model and empirical of the energy-saving indicators. Statistics and Decision. 28(1):32-34.

[3] Zhai, H. J., He, Q., and Huang, P. L. 2007. Research on construction of energy-saving goal system. Energy Conservation Technology. 25(5):450-454.

[4] Xing, L., and Shan, B. G. 2012. The international experiences and revelation for controlling energy consumption cap of China. China Energy. 34(9):14-16.

[5] Comes, E. G. 2007. Modelling undesirable outputs with zero sum gains data envelopment analysis models. Journal of the Operational Research Society. 59(5):616-623.

[6] Phylipsen, G. J. M., Bode, J. W., Blok, K., Merkus, H., and Metz, B. 1998. A Triptych sectoral approach to burden differentiation: GHG emissions in the European bubble. Energy Policy. 26(12):929-943.

[7] Wang, K., Zhang, X., Wei, Y. M., and Yu, S. W. 2013. Regional allocation of $\mathrm{CO} 2$ emissions allowance over provinces in China by 2020. Energy Policy. 54:214-229.

[8] Liu, Z., Shi, Y. R., Yan, J. M., Ou, X. M., and Lieu, J. 2012. Research on the decomposition model for China's national renewable energy total target. Energy Policy. 51:110-120.

[9] Sun, Z. R., Zhou, D. Q., Zhou, P., and Miao, Z. 2012. Quota allocation of China's energy conservation based on environmental ZSG-DEA. Systems Engineering. 30(1):84-90.

[10] Ruan, J. and Ya, Q. 2011. Analysis of the restraint for total energy consumption control to the "Twelfth Five Years Plan" in an area. Science of Science and Management of S. \& T. 32(5):86-91. 